Journal of Engineering and Applied Sciences 14 (21): 8026-8033, 2019

ISSN: 1816-949X

(C) Medwell Journals, 2019

\title{
Alternative Approach of Wind Driven Optimization for Flood Control Rule Curves
}

\author{
${ }^{1}$ Anongrit Kangrang, ${ }^{1}$ Rapeepat Techarungruengsakul, ${ }^{1}$ Rattana Hormwichian and \\ ${ }^{2}$ Ounla Sriwanpheng \\ ${ }^{1}$ Faculty of Engineering, Mahasarakham University, 44150 Maha Sarakham, Thailand \\ ${ }^{2}$ Faculty of Water Resources, National University of Laos, Veintiane, Lao PDR \\ anongrit.k@msu.ac.th
}

\begin{abstract}
Rule curves of reservoir are necessary guides to operate reservoir system in the long run for both flood and draught control. This study proposes the alternative approach of Wind Driven Optimization (WDO) technique to connect with simulation model for searching optimal reservoir rule curves as the flood control area. Minimum average excess water was used as the objective function for searching procedure. The synthetic inflow data of 1,000 events and future inflow were used to evaluate efficiency of the flood control rule curves which showing by situations of water shortage and excess release water in term of frequency, magnitude and duration. The proposed model has applied to determine the optimal flood rule curves of the Nam Oon Reservoir in the Northeast Region of Thailand. The results have shown that the pattern of the obtained rule curves similar to the current rule curves. The optimal flood control rule curves were used to simulate the Nam Oon Reservoir system for evaluating the situation of flood in long term operation. The results have indicated that the situations of flood of the optimal flood control rule curves are smaller than theirs current rule curves both present situation and future situation.
\end{abstract}

Key words: Flood control rule curves, reservoir operation, wind driven optimization, simulation model, optimization technique

\section{INTRODUCTION}

Nowadays flood and draught are serious problems in many countries. In addition, these problems are complexity because of the impact of climate and land use changes. The gold of water management is sustainable development that balances both supply and demand managements. A popular method is non-construction way under supply method like the improvement of reservoir operation because it can be performed quickly. Reservoir rule curves are necessary guidelines using in reservoir operation. The curves indicate either the interval of required water levels or desired storage volumes of each reservoir at any particular month. These rule curves consist of upper rule curves and lower rule curves for controlling monthly stored water in long term operation. However, they need to improve and to find optimal values when used for a long time or if any data are changed such as climate change, land use change, water demand change, water supply change and reservoir characteristic change, etc (Jain et al., 1998; Hormwichian et al., 2018).

There are many optimization techniques have been applied to search optimal rule curves such as dynamic programming (Chaleeraktrakoon and Kangrang, 2007;
Ji et al., 2014), Genetic algorithm (Chang et al., 2005; Hormwichian et al., 2009; Prasanchum and Kangrang, 2018), particle swarm optimization (Suribabu, 2006; Afshar, 2013), ant colony optimization (Afshar et al., 2015), tabu search algorithm (Kangrang et al., 2018) and cuckoo search (Ming et al., 2015), etc. However, most techniques are subject to limitations in their works and are only appropriate for the specific area of use. In addition, each technique has specific applied easy or difficult based on each algorithm.

Nowadays, one of alternative optimization technique can be adapted to find appropriate value is a Wind Driven Optimization (WDO) technique. The WDO algorithm is a new type of nature-inspired global optimization methodology based on atmospheric motion. WDO is an evolutionary adaptive of the air parcel in the atmosphere, finding the best pressure to balance the atmosphere (Pandey and Parhi, 2017). The WDO technique is a population based iterative heuristic global optimization algorithm for multi-dimensional and multi-modal problems with the ability to implement constraints on the search domain. At its core, a population of infinitesimally small air parcels navigates over an $\mathrm{N}$-dimensional search space following Newton's second law of motion which is also, used to describe the motion of air parcels within the

Corresponding Author: Anongrit Kangranga, Faculty of Engineering, Mahasarakham University, 44150 Maha Sarakham, Thailand, anongrit.k@msu.ac.th 
Earth's atmosphere (Ghosh and Das, 2018). WDO is further applied to electromagnetic soptimization problems (Bayraktar et al., 2010, 2011, 2013; Ho et al., 2017). These examples suggest that WDO can, in some cases, out-perform other well-known techniques such as particle swarm optimization and that WDO is well-suited for problems with both discrete and continuous-valued parameters.

Thus, this study proposes the application of an alternative approach of the WDO with reservoir simulation model for searching optimal reservoir rule curves in flood control area. The proposed model was applied to determine the optimal flood rule curves of the Nam Oon Reservoir in the Northeast Region of Thailand. Minimum average excess water and minimum frequency excess water were used as the objective functions for the searching procedure.

\section{MATERIALS AND METHODS}

This study divided the method into 4 parts: collection of data in the study area, modelling reservoir simulation model using water balance concept, application of the proposed WDO with reservoir simulation for searching optimal rule curves, evaluation of obtained rule curves by considering different inflow data (historic, synthetic and future). The details are described as follows.
Study area: The Nam Oon dam is located in Sakolnakorn Province, Thailand. The study area is shown in Fig. 1. The Nam Oon reservoir is located in the Songkharm Basin in the Northeast region of Thailand with an irrigation area of 32,480 ha. The normal storage capacity and average annual inflow are $520 \mathrm{MCM}$ and $431.600 \mathrm{MCM} /$ year, respectively. The historic inflow data records were collected during 1992-2017 (26 years). The 19 years of future inflow data was created by the SWAT Model considering land use change under scenario B2 from 2018-2036 (IPCC., 2013; Supakosol and Kangrang, 2017). The water requirements from Nam Oon reservoir are irrigation, domestic water supply and environmental conservation. Schematic diagrams of the Nam Oon system are presented in Fig. 2.

Reservoir simulation model: A reservoir simulation was created to operate reservoir system on the basis of the water balance concept (HEC-3). These physical reservoir data, hydrologic data, water requirement from the reservoir and related data are required in the operating system. Firstly, available water is calculated by using the water balance concept as presented in Eq. 1. Next, monthly release of water is estimated by considering the calculated available water with release criteria, standard operating rule and reservoir rule curves as showed in Fig. 3:

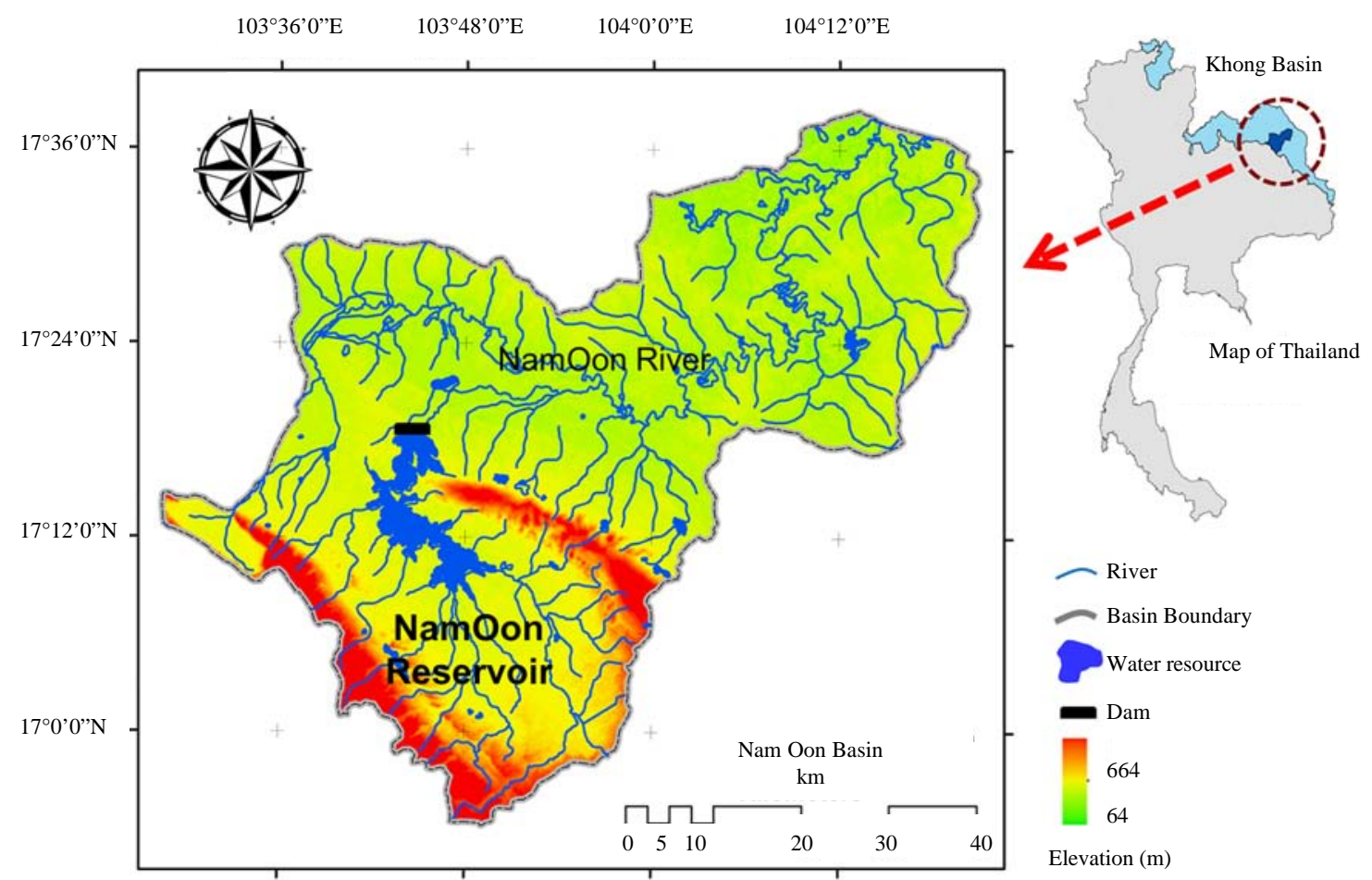

Fig. 1: Location of the Num Oon Reservoir 


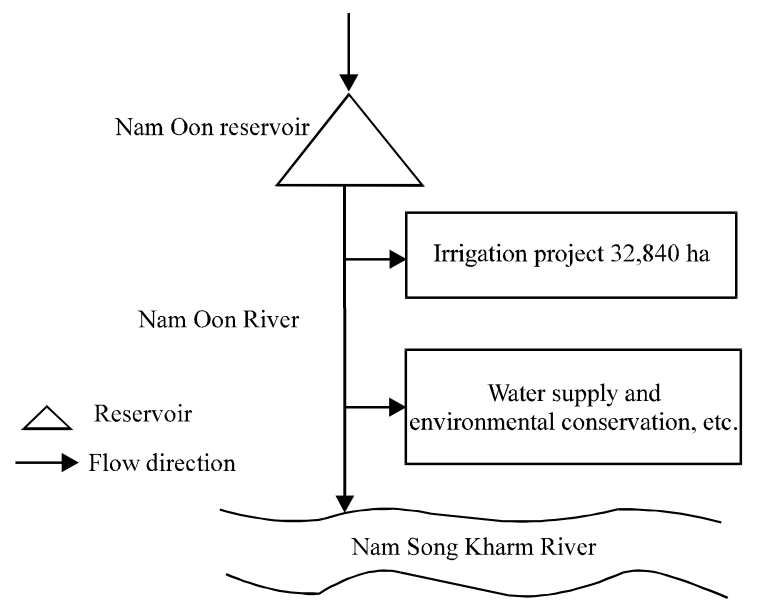

Fig. 2: Schematic diagram of the Num Oon reservoir system

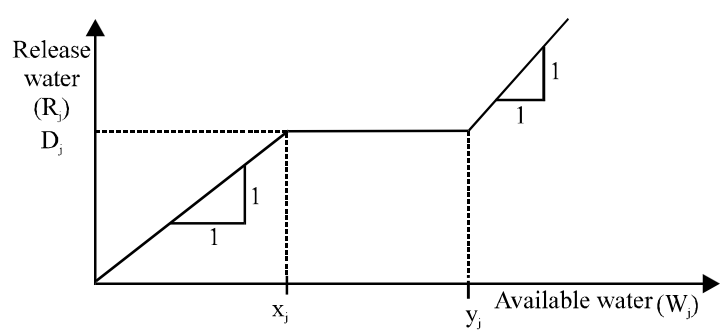

Fig. 3: Standard operating rule

$$
W_{j}=S_{j-1}+I_{j}+P_{j}-E_{j}
$$

Where:

$\mathrm{W}_{\mathrm{j}}=$ The available Water during month $\mathrm{j}$

$S_{j-1}=$ The Stored water at the end of month $j-1$

$I_{j} \quad=$ The Inflow to the reservoir during month $j$

$P_{j}=$ The Precipitation during month $j$

$\mathrm{E}_{\mathrm{j}}=$ The average value of the Evaporation loss during month j

Then, the monthly release of water from the Reservoir $R_{\tau}$ was used to calculate water shortage and excess water situations which can be expressed as the average annual excess water per year (the first objective function for searching) and the frequency excess water per year (the second objective function for searching) as shown in Eq. 2 and 4, respectively. The $x_{j}$ is lower rule curves during month $\mathrm{j}$ and $\mathrm{y}_{\mathrm{j}}$ is upper rule curves during month $\mathrm{j}$ :

$$
\begin{gathered}
\text { Min } A v r_{i}=\left(\frac{1}{n} \sum_{v=1}^{n} S_{p}\right) \\
\text { If } R_{j}>D_{j} ; \text { Then } \operatorname{Sp}_{v}=\sum_{j=1}^{12}\left(R_{j}-D_{j}\right)
\end{gathered}
$$

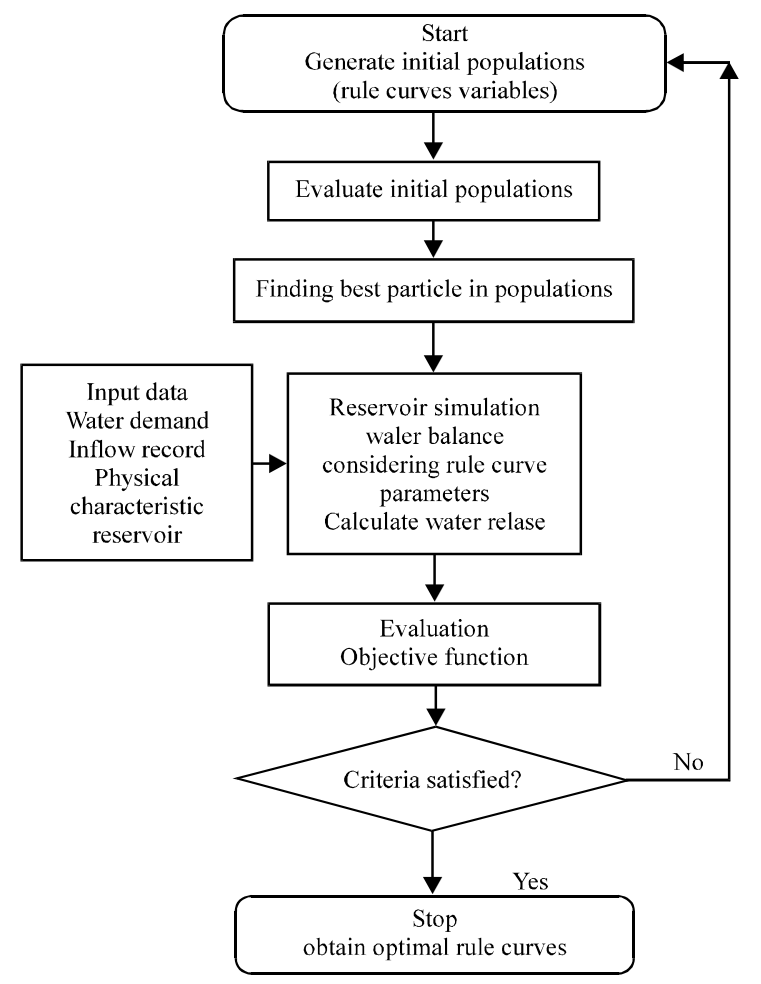

Fig. 4: Application of WDO and reservoir simulation model for searching optimal rule curves

$$
\operatorname{Min} \operatorname{Fre}_{i}=\left(\frac{1}{n} \sum_{v=1}^{n} S_{v}\right)
$$

Where:

$\mathrm{Avr}_{\mathrm{i}}=$ Average excess water per year during iteration i

$\mathrm{Sp}_{\mathrm{v}}=$ The excess water during year $\mathrm{v}$ (year in which releases are higher than the target demand)

$\mathrm{Fre}_{i}=$ Frequency excess water

$\mathrm{Sf}_{\mathrm{v}}=$ The number of annual flood (year that releases higher than target demand)

$\mathrm{i}=$ The iteration number

Application of wind driven optimization with reservoir simulation: The connection of the WDO and reservoir simulation model starts with initialized parameters covering all initial necessary data such as dead storage level, normal high water level, full capacity level, monthly water requirement and monthly inflow data (Fig. 4). Then, model then generates initial populations represents the monthly rule curves of the reservoirs which are defined as the upper rule curves and the lower rule curves (24 decision variables that consist of 12 values for upper rule curves and 12 values for lower rule curves). Next, the initial populations are evaluated and found the best particle in populations. Then, the best particle populations are sent to use in reservoir simulation model. 
Monthly release water was obtained from the reservoir simulation model considering those rule curves and standard operating rule. Next, the released water is used to determine the objective functions that were described in the previous section. Then, evaluations of the objective function are done. After that, the stopping criterion is checked. This procedure is repeated until criteria were met and the optimal rule curves were obtained. The WDO and reservoir simulation model for searching the rule curves is described in Fig. 4.

Evaluation of the obtained rule curves: The obtained rule curves of the WDO were evaluated by using reservoir simulation model considering each inflow case. The first case considered 26 years of historic inflow. The second case 1,000 events of synthetic inflow from 26 years of historic inflow are used under the same conditions. Finally, 19 years future inflow is used to evaluate again. The results of the evaluation will be shown in situations of both water shortage and excess water in term of frequency, magnitude and duration.

\section{RESULTS AND DISCUSSION}

The obtained rule curves of both objective functions for minimum Average excess water (Avr) and minimum Frequency excess water (Fre) are shown in Fig. 5 and 6 , respectively. Figure 5 presents the optimal rule curves of the Nam Oon reservoir using minimized excess water per year as the objective function of the search procedure

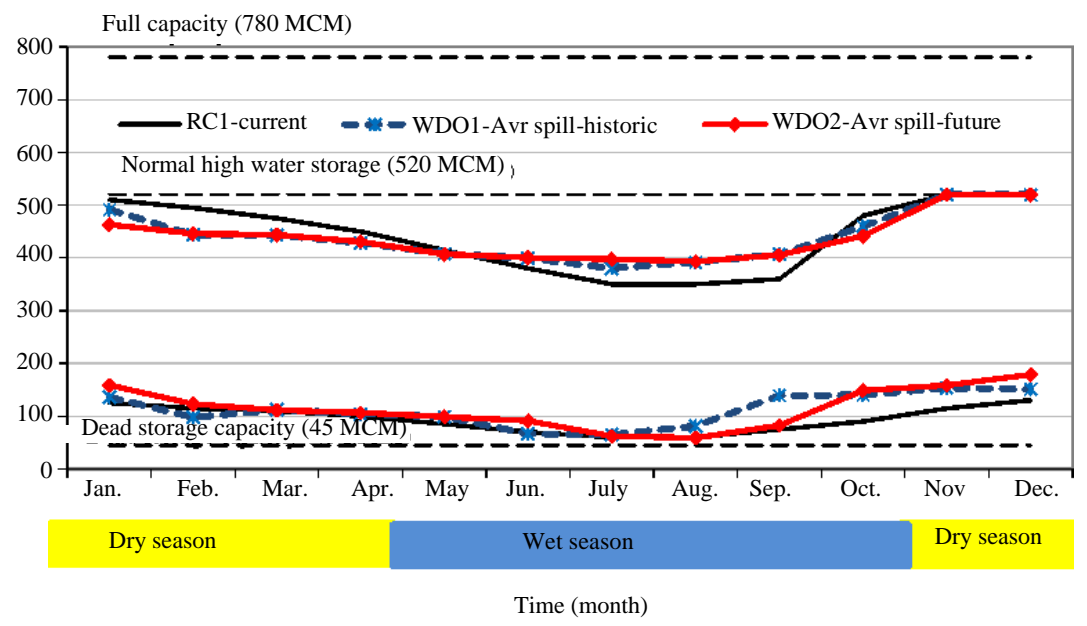

Fig. 5: Optimal rule curves of the Num Oon reservoir using minimum average excess spill water (Avr) as the objective function of the search procedure

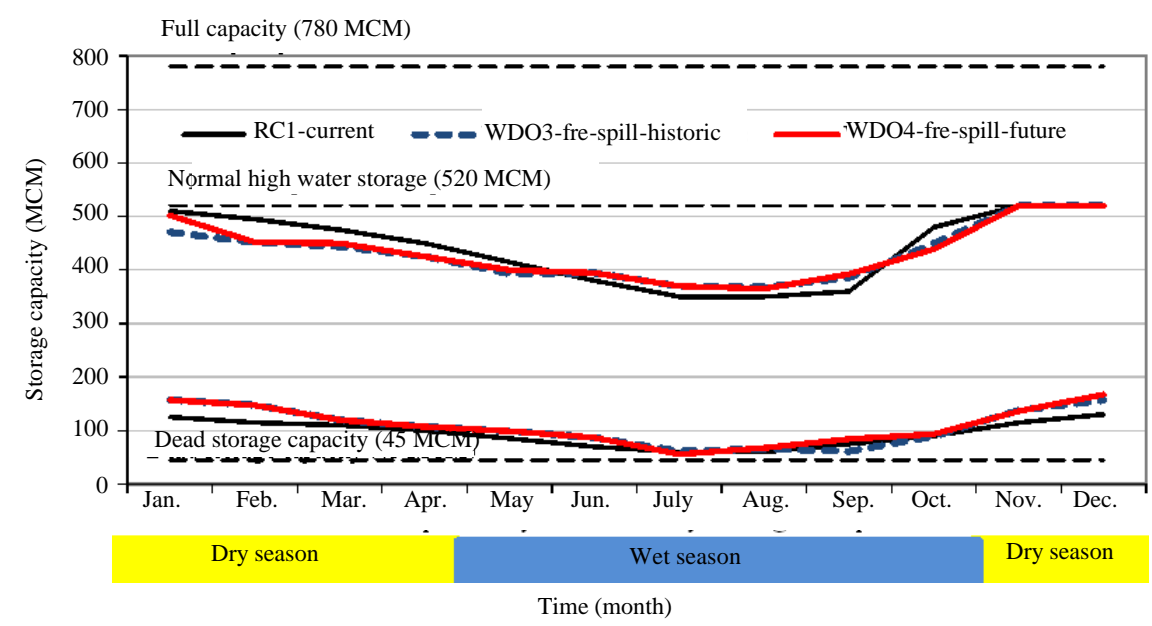

Fig. 6: Optimal rule curves of the Num Oon reservoir using minimum frequency excess water (Fre) as the objective function of the search procedure 
Table 1: The situations of water shortage and excess water of the Nam Oon reservoir considering historic inflow 26 years

\begin{tabular}{|c|c|c|c|c|c|}
\hline \multirow[b]{2}{*}{ Situations/Rule curves } & \multirow[b]{2}{*}{ Frequency (times/y ear) } & \multicolumn{2}{|c|}{ Volume (Million cubic meter) } & \multicolumn{2}{|c|}{ Time period (year) } \\
\hline & & Average & Maximum & Average & Maximum \\
\hline \multicolumn{6}{|l|}{ Water deficit } \\
\hline RC1-current & 0.962 & 44.923 & 152.000 & 12.500 & 15.000 \\
\hline WDO1-Avr spill-historic & 0.462 & 20.846 & 131.000 & 1.714 & 3.000 \\
\hline WDO2-Avr spill-future & 0.538 & 22.923 & 133.000 & 2.000 & 3.000 \\
\hline WDO3-Fre spill-historic & 0.885 & 40.115 & 141.000 & 11.500 & 13.000 \\
\hline WDO4-Fre spill-future & 0.962 & 38.692 & 141.000 & 12.500 & 13.000 \\
\hline \multicolumn{6}{|l|}{ Excess water } \\
\hline $\mathrm{RC} 1$-current & 0.769 & 113.40 & 476.959 & 4.000 & 6.000 \\
\hline WDO1-Avr spill-historic & 0.692 & 89.916 & 486.380 & 3.000 & 5.000 \\
\hline WDO2-Avr spill-future & 0.692 & 92.428 & 511.201 & 3.000 & 5.000 \\
\hline WDO3-Fre spill-historic & 0.731 & 108.85 & 515.740 & 3.167 & 6.000 \\
\hline WDO4-Fre spill-future & 0.731 & 107.09 & 515.740 & 3.167 & 6.000 \\
\hline
\end{tabular}

considering historic inflow (WDO1-Avr spill-historic) and future inflow (WDO2-Avr spill-future) by the proposed WDO Model as well as the current rule curves (RC1-current). They indicate that the pattern of newly obtained rule curves and the current rule curves are similar because of the seasonal inflow effect and the same searching conditions. They, also, indicate that lower rule curves of using historic and future inflow are higher than current rule curves during March to July. This will save water during dry season for next season by decreasing water release. Whereas the upper rule curves of the new obtained rule curves during June to September are higher than current rule curves. This means that they can save more water by keeping high level for next dry season. However, the obtained upper rule curves are lower than the current upper rule curves during October, so, these new rule curves can alleviate flood situation better than the current rule curves because of having more free reserve volume.

Figure 6 shows the optimal rule curves of the Nam Oon reservoir using minimized frequency excess water (Fre) as the objective function of the search procedure considering historic inflow (WDO3-Fre spill-historic) and future inflow (WDO4-Fre spill-future) by the proposed WDO Model and the current Rule Curves ( $\mathrm{RCl}$-current). They indicate that the pattern of newly obtained rule curves and current rule curves are similar because of the seasonal inflow effect and the same searching conditions. They also indicate that lower rule curves of using historic and future inflow (WDO3-Fre spill-historic and WDO4-Fre spill-future) are higher than current rule curves during January to June. This will save store water during the dry season for next season by decreasing water release. In addition, the upper rule curves of the new obtained rule curves during June to September are higher than current rule curves. This means that they can store more water at high level for next dry season. However, the empty reserve volume for flood control protection has been decreased too. Whereas the new obtained upper rule curves are lower than the current upper rule curves in October, hence, these new rule curves can alleviate flood situation better than the current rule curves because they will release water for making free reserve volume.

The efficiency of the new obtained rule curves from all cases of searching was evaluated by operating reservoir simulation with historic inflow data case. The 26 years of monthly inflow data for Nam Oon reservoir were considered in operating reservoir simulation model. Table 1 shows the situations of water shortage and excess water of the Nam Oon reservoir considering historic inflow 26 years in operating reservoir simulation model.

They indicate that the situations of water shortage ( 0.462 times/year, $20.846 \mathrm{MCM} /$ year and 1.714 years for frequency, magnitude and duration, respectively) and excess water (0.692 times/year, 89.916 MCM/year and 3.00 years for frequency, magnitude and duration, respectively) when using WDO rule curves from considering the minimized average excess water as the objective function (WDO1-Avr spill-historic). These are the least as compared with other rule curves. They, also, show that the new obtained rule curves are better at decreasing the situation of water shortage and excess release water (flood control situation) than the current rule curves under historic inflow scenario. In addition, the 1,000 samples of synthetic inflow were generated from 26 years historic inflow data. These 1,000 events were used to simulate under the same conditions. Table 2 shows the situations of water shortage and excess water of the Nam Oon reservoir considering synthetic inflow comprising 1.000 events in operating reservoir simulation model. They indicate that the situations of water shortage $(18.098 \pm 7.851 \mathrm{MCM} /$ year $)$ and excess water (67.386 $\pm 18.292 \mathrm{MCM} /$ year) when using WDO rule curves from considering minimize average excess water as the objective function (WDO1-Avr spill-historic). These are the least as compared with other rule curves. 
Table 2: The situations of water shortage and excess water of the Nam Oon reservoir considering synthetic inflow 1,000 samples

\begin{tabular}{|c|c|c|c|c|c|}
\hline \multirow[b]{2}{*}{ Situations/Rule curves } & \multirow[b]{2}{*}{ Frequency (times/year) } & \multicolumn{2}{|c|}{ Volume (Million cubic meters) } & \multicolumn{2}{|c|}{ Time period (year) } \\
\hline & & Average & Maximum & Average & Maximum \\
\hline \multicolumn{6}{|l|}{ Water deficit } \\
\hline \multicolumn{6}{|l|}{ RC1-current } \\
\hline$\mu$ & 0.971 & 41.586 & 130.189 & 18.238 & 21.056 \\
\hline$\sigma$ & 0.032 & 6.258 & 36.162 & 6.990 & 4.693 \\
\hline \multicolumn{6}{|c|}{ WDO1-Avr spill-historic } \\
\hline$\mu$ & 0.483 & 18.098 & 109.499 & 2.419 & 4.825 \\
\hline$\sigma$ & 0.109 & 7.851 & 28.958 & 0.863 & 2.038 \\
\hline \multicolumn{6}{|c|}{ WDO2-Avr spill-future } \\
\hline$\mu$ & 0.518 & 19.159 & 109.414 & 2.566 & 5.194 \\
\hline$\sigma$ & 0.106 & 8.094 & 28.427 & 0.925 & 2.143 \\
\hline \multicolumn{6}{|l|}{ WDO3-Fre spill-historic } \\
\hline$\mu$ & 0.905 & 37.252 & 123.710 & 10.394 & 15.256 \\
\hline$\sigma$ & 0.060 & 6.658 & 35.398 & 5.998 & 5.245 \\
\hline \multicolumn{6}{|l|}{ WDO4-Fre spill-future } \\
\hline$\mu$ & 0.972 & 34.686 & 120.609 & 20.032 & 22.053 \\
\hline$\sigma$ & 0.032 & 6.929 & 33.899 & 6.472 & 4.181 \\
\hline \multicolumn{6}{|l|}{ Excess water } \\
\hline \multicolumn{6}{|l|}{ RC1-current } \\
\hline$\mu$ & 0.676 & 90.509 & 356.605 & 3.376 & 7.017 \\
\hline$\sigma$ & 0.100 & 19.573 & 74.965 & 1.402 & 2.960 \\
\hline \multicolumn{6}{|c|}{ WDO1-Avr spill-historic } \\
\hline$\mu$ & 0.551 & 67.386 & 326.423 & 2.579 & 5.247 \\
\hline$\sigma$ & 0.113 & 18.292 & 80.925 & 0.902 & 2.201 \\
\hline \multicolumn{6}{|l|}{ WDO2-Avr spill-future } \\
\hline$\mu$ & 0.559 & 68.412 & 327.202 & 2.597 & 5.300 \\
\hline$\sigma$ & 0.111 & 18.266 & 80.585 & 0.916 & 2.202 \\
\hline \multicolumn{6}{|c|}{ WDO3-Fre spill-historic } \\
\hline$\mu$ & 0.651 & 84.830 & 346.469 & 3.153 & 6.534 \\
\hline$\sigma$ & 0.102 & 19.345 & 75.980 & 1.202 & 2.657 \\
\hline \multicolumn{6}{|l|}{ WDO4-Fre spill-future } \\
\hline$\mu$ & 0.635 & 82.019 & 344.217 & 3.018 & 6.260 \\
\hline 0 & 0.102 & 19.156 & 76.846 & 1.146 & 2.566 \\
\hline
\end{tabular}

Table 3: The situations of water shortage and excess water of the Nam Oon reservoir considering future inflow 19 years

\begin{tabular}{|c|c|c|c|c|c|}
\hline \multirow[b]{2}{*}{ Situations/Rule curves } & \multirow[b]{2}{*}{ Frequency (times/year) } & \multicolumn{2}{|c|}{ Volume (Million cubic meter) } & \multicolumn{2}{|c|}{ Time period (year) } \\
\hline & & Average & Maximum & Average & Maximum \\
\hline \multicolumn{6}{|l|}{ Water deficit } \\
\hline $\mathrm{RC} 1$-current & 0.632 & 20.316 & 57.000 & 3.000 & 5.000 \\
\hline WDO1-Avr spill-historic historic & 0.316 & 4.737 & 55.000 & 2.000 & 4.000 \\
\hline WDO2-Avr spill-future & 0.263 & 3.895 & 46.000 & 1.667 & 3.000 \\
\hline WDO3-Fre spill-historic & 0.526 & 15.158 & 55.000 & 2.500 & 5.000 \\
\hline WDO4-Fre spill-future & 0.789 & 13.737 & 56.000 & 3.750 & 9.000 \\
\hline \multicolumn{6}{|l|}{ Excess water } \\
\hline $\mathrm{RC} 1$-current & 0.947 & 234.065 & 522.880 & 9.000 & 17.000 \\
\hline WDO1-Avr spill-historic & 0.947 & 217.915 & 519.044 & 9.000 & 17.000 \\
\hline WDO2-Avr spill-future & 0.947 & 217.066 & 517.454 & 9.000 & 17.000 \\
\hline WDO3-Fre spill-historic & 0.947 & 227.611 & 522.88 & 9.000 & 17.000 \\
\hline WDO4-Fre spill-future & 0.947 & 225.891 & 522.88 & 9.000 & 17.000 \\
\hline
\end{tabular}

Whereas the results of using current rule curves for evaluation gave the highest value. They, also, present that the new obtained rule curves from the proposed WDO are better decreasing both water shortage situation and flood control situation than the current rule curves under the synthetic inflow scenario.

Moreover, the efficiency of the newly obtained rule curves of Nam Oon reservoir were evaluated by the operating reservoir simulation considering 19 years of future inflow (2018-2036) under land use change and climate change of B2 scenario (IPCC., 2013;
Supakosol and Kangrang, 2017). Table 3 shows the situations of water shortage and excess water of the Num Oon reservoir considering future inflow 19 years (2018-2036). They indicated that the average magnitudes of the water shortage $(3.895 \mathrm{MCM} /$ year $)$ and excess water (217.066 MCM/year) using the future rule curves (WDO2-Avr spill-future) are the least as compared to the other rule curves. In addition, the frequencies and duration times of the water shortage and excess water of using the future rule curves (WDO2-Avr spill-future) are the lowest too. Therefore, the future obtained rule curves 
(WDO2-Avr-spill-future) can alleviate situations of both flood and drought better than the current rule curves in future scenario too.

\section{CONCLUSION}

This study applied Wind Driven Optimization (WDO) with a reservoir simulation model for searching optimal rule curves of the Nam Oon Reservoir in the Northeast Region of Thailand. There were two objective functions that were applied to the search process minimum Average excess water (Avr) and minimum Frequency excess water (Fre). The future inflow and synthetic inflow data were used to simulate the reservoir system for evaluating the performance of the obtained rule curves in term of excess water situation or flood situation.

The results indicated that the proposed model with two objective functions provided the new rule curves (WDO-Avr and WDO-Fre). The patterns of these rule curves (WDO-Avr and WDO-Fre) are similar due to seasonal inflow effect and the same searching conditions. However, there are some different points, especially, during the rainy season. Furthermore, the results also, reveal that the rule curves from using minimum Average excess water (WDO-Avr) and considering historic inflow in searching process can alleviate excess water situation better than other rule curves in both historic inflow and synthetic inflow situations.

\section{RECOMMENDATIONS}

In addition, the obtained rule curves from using minimum Average excess water (WDO-Avr) and considering future inflow in searching process can alleviate situations of flood better than the current rule curves in future inflow situation too.

\section{ACKNOWLEDGEMENTS}

This research was financially supported by Mahasarakham University and National Research Council of Thailand Grant Year 2019, the researchers would like to acknowledge Mahasarakham University and National Research Council of Thailand.

\section{REFERENCES}

Afshar, A., F. Massoumi, A. Afshar and M.A. Marino, 2015. State of the art review of ant colony optimization applications in water resource management. Water Resour. Manage., 29: 3891-3904.
Afshar, M.H., 2013. Extension of the constrained particle swarm optimization algorithm to optimal operation of multi-reservoirs system. Int. J. Electr. Power Energy Syst., 51: 71-81.

Bayraktar, Z., J.P. Turpin and D.H. Werner, 2011. Nature-inspired optimization of high-impedance metasurfaces with ultrasmall interwoven unit cells. IEEE. Antennas Wirel. Propag. Lett., 10: 1563-1566.

Bayraktar, Z., M. Komurcu and D.H. Werner, 2010. Wind Driven Optimization (WDO): A novel nature-inspired optimization algorithm and its application to electromagnetics. Proceedings of the 2010 IEEE International Symposium on Antennas and Propagation Society (APSURSI), July 11-17, 2010, IEEE, Toronto, ON, Canada, pp: 1-4.

Bayraktar, Z., M. Komurcu, J.A. Bossard and D.H. Werner, 2013. The wind driven optimization technique and its application in electromagnetics. IEEE. Trans. Antennas Propag., 61: 2745-2757.

Chaleeraktrakoon, C. and A. Kangrang, 2007. Dynamic programming with the principle of progressive optimality for searching rule curves. Can. J. Civil Eng., 34: 170-176.

Chang, J.F., L. Chen and C.L. Chang, 2005. Optimizing the reservoir operating rule curves by genetic algorithms. Hydrol. Process., 19: 2277-2289.

Ghosh, T.K. and S. Das, 2018. Efficient job scheduling in computational grid systems using wind driven optimization technique. Intl. J. Appl. Metaheuristic Comput., 9: 49-59.

Ho, S.L., S. Yang, Y. Bai and Y. Li, 2017. A wind driven optimization-based methodology for robust optimizations of electromagnetic devices under interval uncertainty. IEEE. Trans. Magn., 53: 1-4.

Hormwichian, R., A. Kangrang and A. Lamom, 2009. A conditional genetic algorithm model for searching optimal reservoir rule curves. J. Applied Sci., 9: 35753580.

Hormwichian, R., J. Tongsiri and A. Kangrang, 2018. Multipurpose rule curves for multipurpose reservoir by conditional genetic algorithm. Intl. Rev. Civil Eng., 9: 114-121.

IPCC., 2013. Working group I contribution to the IPCC fifth assessment report, climate change 2013: The physical science basis, summary for policymakers. IPCC, Draft, September 2013, Geneva, Switzerland.

Jain, K.S., K.M. Goel and K.P. Agarwal, 1998. Reservoir operation study of sabamati system, India. J. Water Res. Plan. Manage., 124: 31-38. 
Ji, C., Z. Jiang, P. Sun, Y. Zhang and L. Wang, 2014. Research and application of multidimensional dynamic programming in cascade reservoirs based on multilayer nested structure. J. Water Resour. Plann. Manage., Vol. 141, No. 7. 10.1061/(ASCE) WR. 1943-5452.0000489

Kangrang, A., H. Prasanchum and R. Hormwichian, 2018. Development of future rule curves for multipurpose reservoir operation using conditional genetic and Tabu search algorithms. Adv. Civil Eng., 2018: 1-10.

Ming, B., J.X. Chang, Q. Huang, Y.M. Wang and S.Z. Huang, 2015. Optimal operation of multi-reservoir system based-on cuckoo search algorithm. Water Resour. Manage., 29: 5671-5687.
Pandey, A. and D.R. Parhi, 2017. Optimum path planning of mobile robot in unknown static and dynamic environments using fuzzy-wind driven optimization algorithm. Defence Technol., 13: 47-58.

Prasanchum, H. and A. Kangrang, 2018. Optimal reservoir rule curves under climatic and land use changes for Lampao Dam using genetic algorithm. KSCE. J. Civil Eng., 22: 351-364.

Supakosol, J. and A. Kangrang, 2017. Assessment of soil loss and nutrient depletion due to climate change impact in the SongKhram Basin, Thailand. Int. J. Ecol. Dev., 32: 53-66.

Suribabu, C.R., 2006. Particle swarm optimisation techniques for deriving operation policies for maximum hydropower generation: A case study. Int. J. Ecol. Dev., 4: 68-85. 